\title{
Butyrate and Subacute Ruminal Acidosis Affect Abundance of Membrane Proteins Involved with Proton and Short Chain Fatty Acid Transport in the Rumen Epithelium of Dairy Cows
}

\author{
${ }^{1}$ Anne Hermen Laarman, ${ }^{1}$ Louis Dionissopoulos, ${ }^{1}$ Ousama AlZahal, \\ ${ }^{2}$ Sabrina Louise Greenwood, ${ }^{1}$ Michael Alexander Steele and ${ }^{1}$ Brian William McBride \\ ${ }^{1}$ Department of Animal and Poultry Sciences, University of Guelph, Guelph, Canada \\ ${ }^{2}$ Department of Animal Science, University of Vermont, Burlington, VT, USA
}

Received 2013-10-18; Revised 2013-10-21; Accepted 2013-11-27

\begin{abstract}
The objective of this study was to elucidate the effects of butyrate on the Short Chain Fatty Acids (SCFA) membrane transport proteins and proton membrane transport proteins in the rumen epithelium. Sixteen midlactation cows were fed a 44\% Non-Fibre Carbohydrate (NFC) diet and divided into a control treatment and a butyrate treatment. For 7 days, the cows on the control treatment received a carrier treatment and the cows on the butyrate treatment received a ruminal butyrate dose at the rate of $2.5 \%$ of Dry Matter Intake (DMI). Rumen $\mathrm{pH}$ was measured on days 6 and 7 and rumen biopsies were taken on days 1 and 7. Rumen $\mathrm{pH}$ measurements confirmed the occurrence of ruminal acidosis in both treatment groups, defined as a rumen $\mathrm{pH}$ of 5.6 for at least $3 \mathrm{~h}$ per day. Between the control and butyrate treatment, there was no difference in rumen $\mathrm{pH}$ profile. Immunofluorescence analysis performed on longitudinal ruminal papillae cross-sections showed that for the duration of the study, protein abundance in the stratum basale increased for Monocarboxylate Cotransporter Isoform 1 (MCT1), sodium/proton exchanger isoform 3 (NHE3) and sodium/Bicarbonate Cotransporter Isoform 1 (NBC1). There was a time*treatment interaction for MCT1 and $\mathrm{NBC1}$, with the butyrate treatment group showing a higher abundance of MCT1 and a lower abundance of NBC1 at day 7. Luminal butyrate appears to increase SCFA uptake capacity by increasing the abundance of MCT1 transport proteins on the basolateral membrane and decreasing basolateral bicarbonate uptake capacity through decreased $\mathrm{NBCl}$ protein expression. These effects decrease bicarbonate uptake capacity through $\mathrm{NBCl}$ and help to offset the increased MCT1, since MCT also creates alkalotic pressure by expelling protons from the cytosol.
\end{abstract}

Keywords: Butyrate, Epithelium, Transport Proteins

\section{INTRODUCTION}

Short chain fatty acids (SCFA) are a major source of energy for rumen epithelial cells (Bergman, 1990). Historically, SCFA were thought to passively diffuse through the rumen epithelium, but more recently, evidence has emerged that uptake of SCFA is primarily achieved through facilitated exchange using a number of uptake mechanisms (Aschenbach et al., 2009). In human adenocarcinoma cells, the two major mechanisms are a high affinity/low capacity Monocarboxylate/proton
Cotransporter isoform 1 (MCT1) and a low affinity/high capacity butyrate/bicarbonate antiporter (Lecona et al., 2008). Several models of rumen epithelial transport have been developed in recent years (Connor et al., 2010; Gabel et al., 2002), which include anion exchanger isoform 2 (AE2), sodium/proton exchanger isoform 3 (NHE3) on the apical side and MCT1, sodium/proton exchanger isoform 1 (NHE1) and sodium/bicarbonate cotransporter isoform 1 (NBC1) on the basolateral side (Fig. 1).

Facilitated uptake of SCFA highlights the im-portance of rumen epithelium functionality and physiology.

Corresponding Author: Anne Hermen Laarman, Department of Animal and Poultry Sciences, University of Guelph, Guelph, Canada 


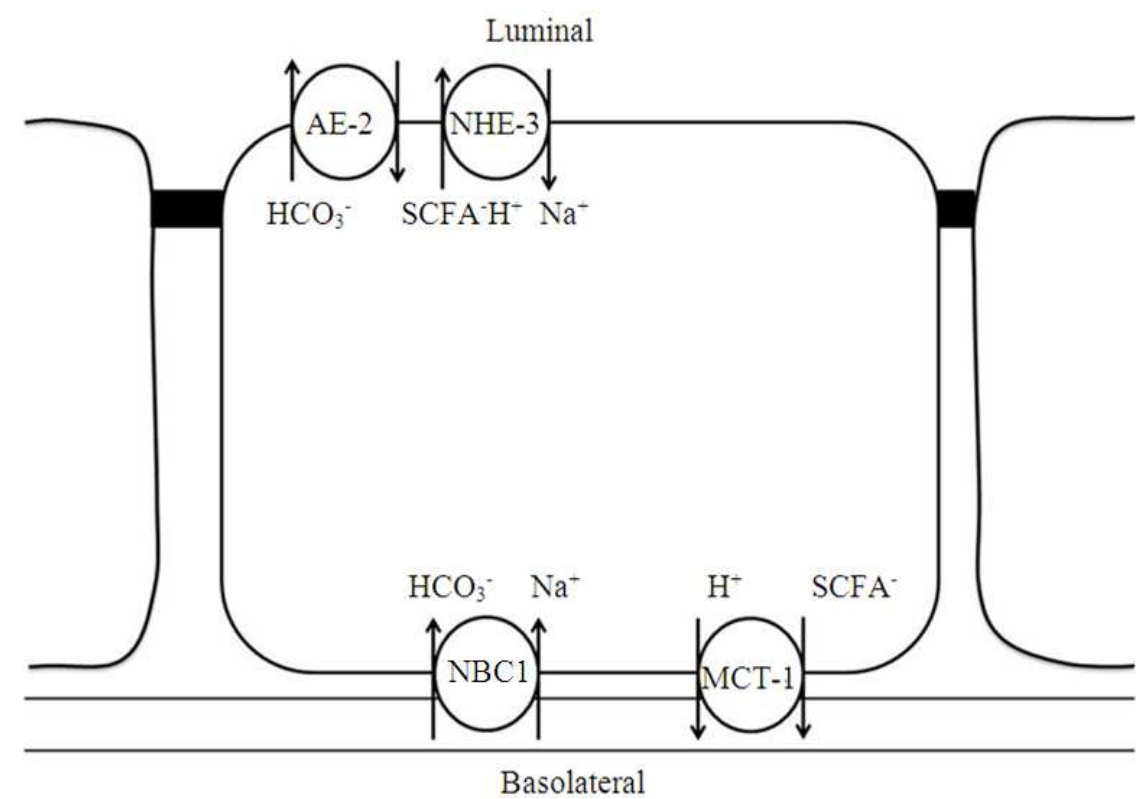

Fig. 1. Model of membrane transport protons in the rumen epithelium involved in SCFA and proton transport. Adapted from Laarman (2011)

Higher uptake rates of acetate, for instance, have been linked to an increased resistance to Subacute Ruminal Acidosis (SARA) (Penner et al., 2009). When the accumulation of protons from the fermentation of rapidly fermentable Non-Fibre Carbohydrates (NFC) overwhelms the ability of the rumen to buffer or neutralize the protons, the $\mathrm{pH}$ drops and SARA can occur (Allen, 1997). In light of these recent findings and the continuing importance of mitigating the costly impacts of SARA (Krause and Oetzel, 2006), the importance of epithelial transport mechanisms has become apparent.

One principal candidate for modulating rumen epithelial transport mechanisms is butyrate, a bioactive SCFA. Treatment with butyrate increased cellular uptake of butyrate in butyrate-sensitive BCS-TC2 colon adenocarcinoma cells (Lecona et al., 2008). Also, within the promoter region of NHE3, there exists a butyrateresponse element (Kiela et al., 2007). Most of the bioactivity of butyrate studied to this point has primarily been attributed to its ability to hyperacetylate histone proteins through its action on the Histone Deacetylase Complex (HDAC) (Davie, 2003; Mathew et al., 2010), which potentially affects the expression of multiple genes. Although butyrate's effects on gene expression and transport rates are well-studied, it is unclear which membrane transport mechanisms butyrate affects at the protein level.
The objective of this study was to investigate the effects of butyrate on ruminal epithelial transport proteins in cows with SARA. We hypothesized that butyrate would serve to increase the abundance of membrane transport proteins such as MCT1, closely associated with SCFA uptake. Since the effects of butyrate on transport rates have been established, identifying the role of protein expression is an important step in solidifying our under-standing of SCFA uptake in ruminants.

\section{MATERIALS AND METHODS}

\subsection{Animals and Treatment}

The experiment was carried out as described by Dionissopoulos et al. (2013) and approved by the University of Guelph Animal Care Committee using guidelines of the Canadian Council for Animal Care. Sixteen mid-lactation, rumen-cannulated cows were fed a mid-lactation Total Mixed Ration (TMR) that included a concentrate mix formulated to elevate the NFC content of the diet from 40.0 to $44.0 \%$ of dry matter (Dionissopoulos et al., 2013). Cows were blocked by Days In Milk (DIM) and assigned either a control or a butyrate treatment. On the butyrate treatment, cows were dosed with butyrate (Proformix; Probiotech Inc., Saint Hyacinthe, QC) at a rate of $2.5 \%$ of their average daily Dry Matter Intake (DMI); on the control treatment, cows 
were dosed with a carrier, in this case a paper bag. Butyrate was dosed at $10.00 \mathrm{~h}$ and $13.30 \mathrm{~h}$ daily, to correspond with feeding times.

\subsection{TMR, Milk, Rumen and Blood Sampling}

Milk production and DMI were measured daily and milking occurred at 5.30 and $16.00 \mathrm{~h}$ daily. Rumen $\mathrm{pH}$ was measured on day 6 and 7 of the experiment using an indwelling rumen $\mathrm{pH}$ system (Alzahal et al., 2007). Rumen fluid and blood were sampled on days 1 and 7 at $16.30 \mathrm{~h}$. Rumen fluid was harvested from the rumen ventral sac and squeezed through 4 layers of cheesecloth, then snap frozen in liquid nitrogen. Blood was harvested from the tail vein and processed as previously described (Dionissopoulos et al., 2013).

Milk samples were pooled and analyzed for milk components (CanWest DHI Laboratory, Guelph, ON, Canada). Blood samples were processed and analyzed for serum $\beta$-Hydroxybutyrate (BHBA) by the Animal Health Laboratory (Guelph, ON, Canada) using established methods (Williamson et al., 1962). Rumen fluid was analyzed for SCFA by gas chromatography (Steele et al., 2011).

\subsection{Histology and Immunofluorescence}

Approximately 20 papillae were harvested from the rumen and washed 3 times in ice-cold PBS, then stored in $4 \%$ formalin solution for $24 \mathrm{~h}$. At that point, papillae were transferred to $70 \%$ ethanol solution and mounted in paraffin wax by Animal Health Laboratories (Guelph, $\mathrm{ON}$, Canada). In each sample, an $\mathrm{H}$ and $\mathrm{E}$ stain was done according to established protocols and the images were taken using an Olympus BX60 light microscope mounted with an Olympus DP71 camera (Richmond Hill, ON, Canada). Images were analyzed for papillae sloughing on a scale of 1-5 using a scoring rubric previously developed in our lab (Steele et al., 2013). Briefly, papillae images were assessed a score of 1 for a completely intact epithelium; 2, 3, or 4 for increasing degrees of sloughing and papillae showing extensive sloughing were assessed a 5. Scoring was blind and involved multiple technical replicates per biological sample. To further control for bias, scoring was done simultaneously by 2 people and person-toperson variation was analyzed.

For immunofluorescence analysis, mounted samples were sectioned longitudinally ( $5 \mu \mathrm{m}$ thick) and were mounted on charged microscope slides (Fisher, Whitby, ON, Canada). After paraffin removal, samples were incubated in $10 \mathrm{mM}$ sodium citrate buffer (Fisher, Whitby, ON, Canada) at $95^{\circ} \mathrm{C}$ for antigen retrieval, then blocked and permeabilized with $10 \%$ goat serum and $0.3 \%$ Triton-X100 blocking buffer. Sections were incubated with primary antibody (1:50 dilution) at room temperature for $90 \mathrm{~min}$, washed 3 times with PBS and then incubated with fluorescent secondary antibody (Fisher, Whitby, ON, Canada) for $30 \mathrm{~min}$ at room temperature. Slides were mounted with ProLong AntiFade reagent, including DAPI nuclear stain (Life Sciences, Burlington, ON, Canada). For each primary antibody, a negative control without primary antibody was also stained.

Immunofluorescence was detected using a Leica TCS SP5 Upright confocal fluorescent microscope (Leica Micro Systems, Mannheim, Germany). Smart Gain and Offset were adjusted for each target protein so that the strongest signal did not show extensive pixel saturation. For each blinded sample, 3 images were taken of 3 papillae, totaling 9 images per biological sample. Signal intensity was analyzed using ImageJ (National Center for Biotechnology Information, Bethesda, MD, USA), using a modified approach described by Gavet and Pines (2010). Specifically, similar-sized cells from the stratum basale were visually identified in each image and the whole cell signal quantified. Then, an area beside the papilla was quantified for background signal correction. The corrected whole cell signal was calculated using the formula (Gavet and Pines, 2010):

$$
\mathrm{WCS}=\mathrm{ID}_{\text {cell- }}\left(\mathrm{A}_{\text {cell }} * \mathrm{M}_{\text {background }}\right)
$$

Where:

WCS = The Whole Cell Signal

IDcell = The integrated density of the cell

Acell = The surface area of the cell

Mbackground $=$ The mean background signal

\subsection{Statistics}

Data were analyzed using PROC MIXED of SAS 9.2 (SAS Institute), using the model:

$$
\mathrm{Y}=\mu+\mathrm{D}_{\mathrm{i}}+\mathrm{T}_{\mathrm{j}}+\mathrm{D}^{*} \mathrm{~T}_{\mathrm{ij}}+\varepsilon_{\mathrm{ijk}}
$$

Where:

$\mathrm{Y} \quad=$ The dependant variable

$\mu \quad=$ The variable mean

$\mathrm{D}_{\mathrm{i}} \quad=$ The fixed effect of treatment

$\mathrm{T}_{\mathrm{j}} \quad=$ The fixed effect of time

$\mathrm{D}^{*} \mathrm{~T}_{\mathrm{ij}}=$ The interaction of time and treatment

$\varepsilon_{\mathrm{ijk}} \quad=$ The residual error

Cow within treatment was used as a repeated variable, along with 5 variance/covariance structures. The variance/covariance structure with the lowest AIC and BIC values were used for statistical analysis. 


\section{RESULTS}

\subsection{DMI, Milk, Rumen and Blood Responses}

The effects of butyrate supplementation on DMI, milk and rumen responses have been described previously (Dionissopoulos et al., 2013). Actual NFC content was $44.0 \%$ of DMI; serum BHBA was elevated fourfold in the butyrate treatment compared to control on both day 1 and day 7 (Dionissopoulos et al., 2013). Rumen $\mathrm{pH}$ traces confirmed the occurrence of SARA in both treatments, with no significant difference in $\mathrm{pH}$ measurements between control and butyrate treatments (Dionissopoulos et al., 2013). Total SCFA was higher in butyrate than in control in day 1 $(92.76 \pm 4.51$ Vs $78.87 \pm 4.51 \mathrm{mM})$ but not on day 7 $(87.59 \pm 4.51 \quad$ Vs $\quad 81.82 \pm 4.51 \quad \mathrm{mM})$. Butyrate concentrations were higher in the butyrate treatment than in the control treatment on both day $1(22.60 \pm 0.94$ Vs $9.88 \pm 0.94 \mathrm{mM})$ and on day $7(21.60 \pm 0.94 \mathrm{Vs}$ $8.60 \pm 0.94 \mathrm{mM}$ ); (Dionissopoulos et al., 2013).

\subsection{Immunofluorescence and Histochemistry}

Exogenous butyrate addition resulted in increased abundance of MCT-1 over the 7 days of the experiment, with both control treatment $(11043 \pm 953$ Vs $11275 \pm 953$ A.U.; p < 0.01) and the butyrate treatment $(8996 \pm 1018$ Vs $14747 \pm 953$ A.U.; $p=0.01)$ increasing between days 1 and 7, respectively (Fig. 2 and Table 1). Analysis of MCT-1 protein abundance also showed a treatment*time interaction $(\mathrm{p}=0.01)$, although no effect of treatment was reported $(p=0.48)$. For NHE-1, the treatment effect $(\mathrm{p}=0.85)$, time effect $(p=0.26)$ and $\operatorname{diet}^{*}$ time interaction $(p=0.98)$ were not statistically significant (Fig. 3). Abundance of NHE-3 was significantly affected by time (Fig. 4), increasing from day 1 to day 7 in the control treatment $(9536 \pm 1619$ vs. $13598 \pm 1461$ A.U.; $p=0.03)$ and in the butyrate treatment $(10023 \pm 1698$ Vs $11828 \pm 1400$ A.U.; $\mathrm{p}=0.03)$. No significant effects of treatment or treatment*time were observed. Protein abundance of NBC-1 was increased in both control $(8897 \pm 878$ Vs $15065 \pm 992)$ and butyrate treatments $(9458 \pm 878 \mathrm{Vs}$ $11122 \pm 992$ ) between days 1 and 7 , respectively $(\mathrm{p}<0.01$; Fig. 5). In the NBC1 protein abundance, there was also a significant time*treatment interaction $(\mathrm{p}=$ $0.01)$. Papillae sloughing was not significantly different between treatments (Fig. 6)".

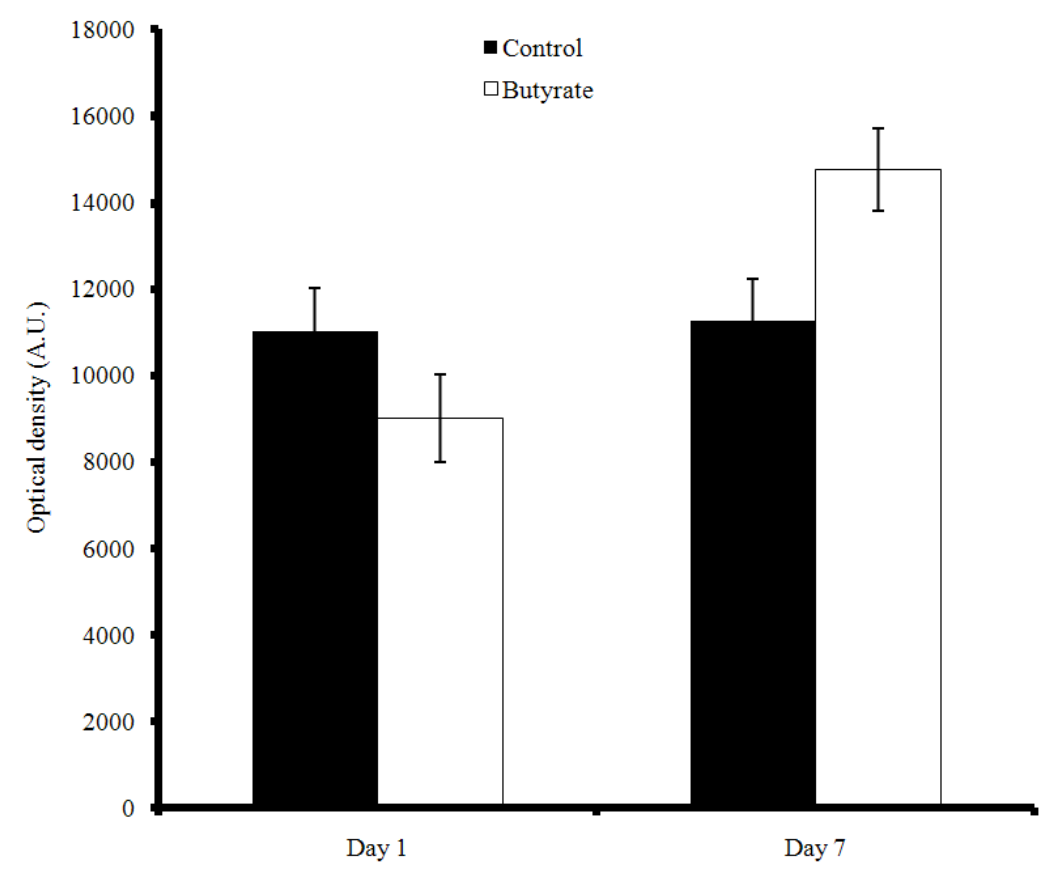

Fig. 2. MCT1 protein expression in the rumen epithelium stratum basale of Holstein cows fed a high NFC TMR with and without exogenous butyrate dosed at $2.5 \% \mathrm{DMI}$ 
Anne Hermen Laarman et al. / American Journal of Animal and Veterinary Sciences 8 (4): 220-229, 2013

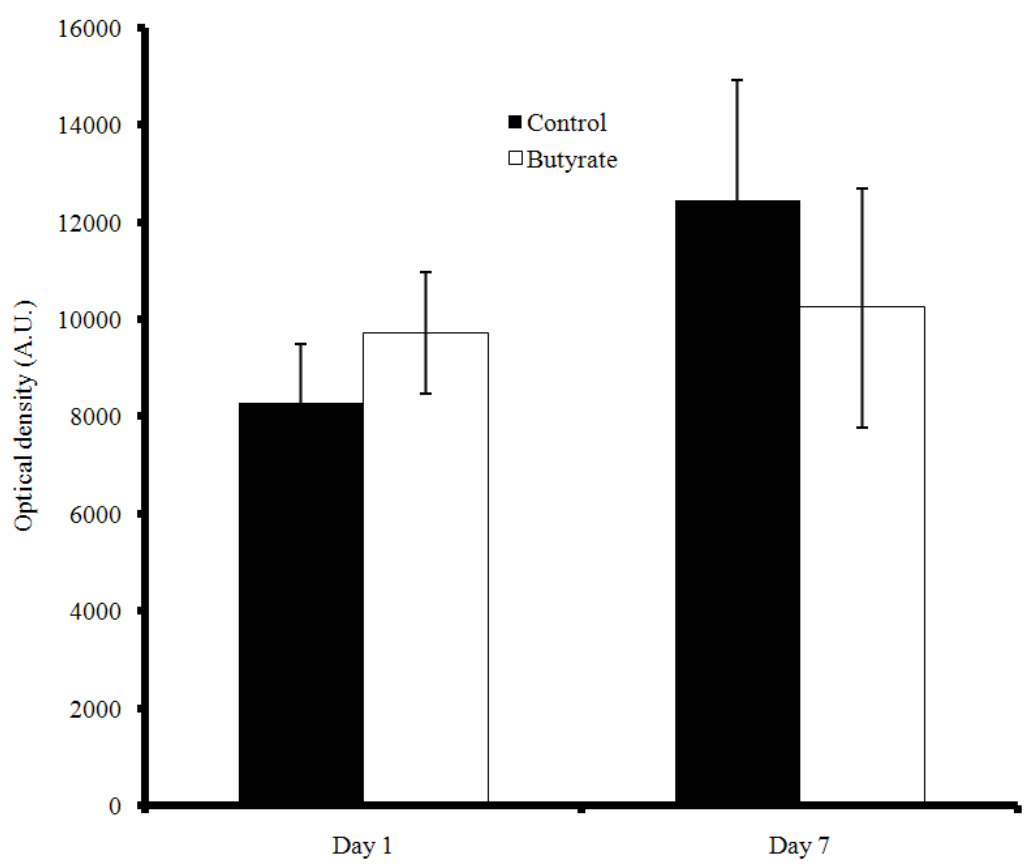

Fig. 3. NHE1 protein expression in the rumen epithelium stratum basale of Holstein cows fed a high NFC TMR with and without exogenous butyrate dosed at 2.5\% DMI

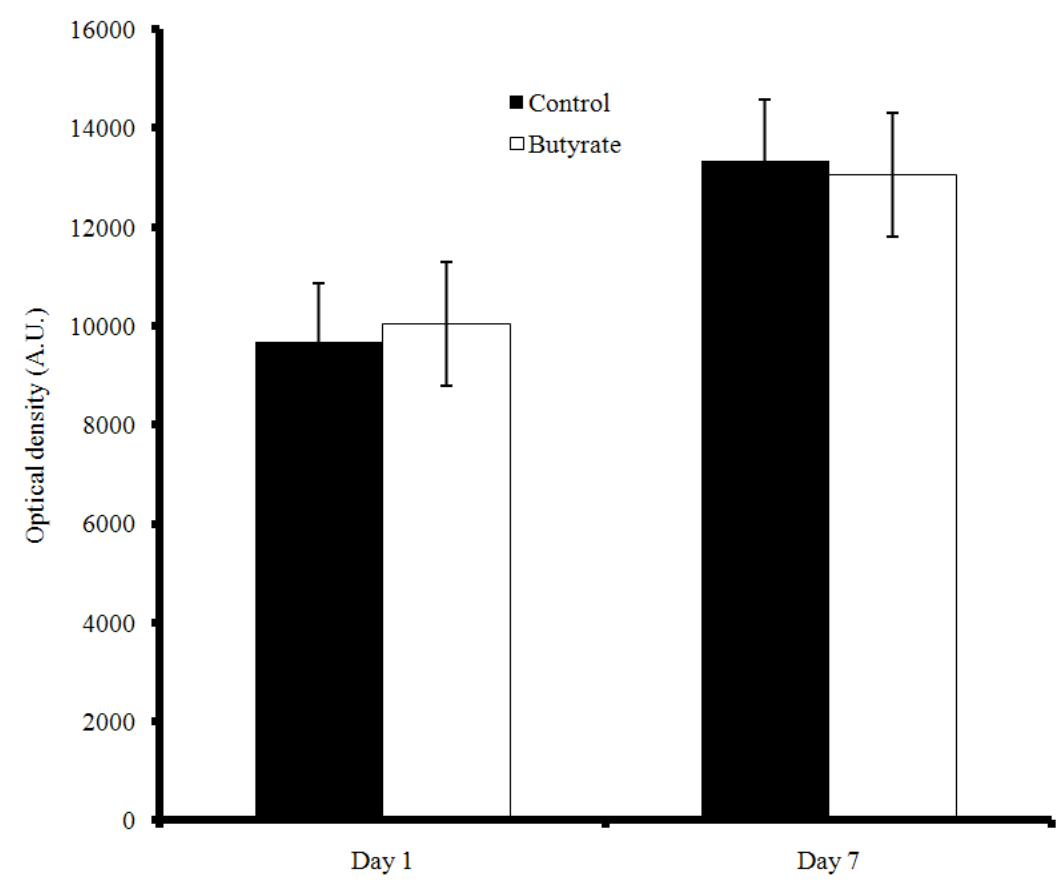

Fig. 4. NHE3 protein expression in the rumen epithelium stratum basale of Holstein cows fed a high NFC TMR with and without exogenous butyrate dosed at $2.5 \%$ DMI 
Anne Hermen Laarman et al. / American Journal of Animal and Veterinary Sciences 8 (4): 220-229, 2013

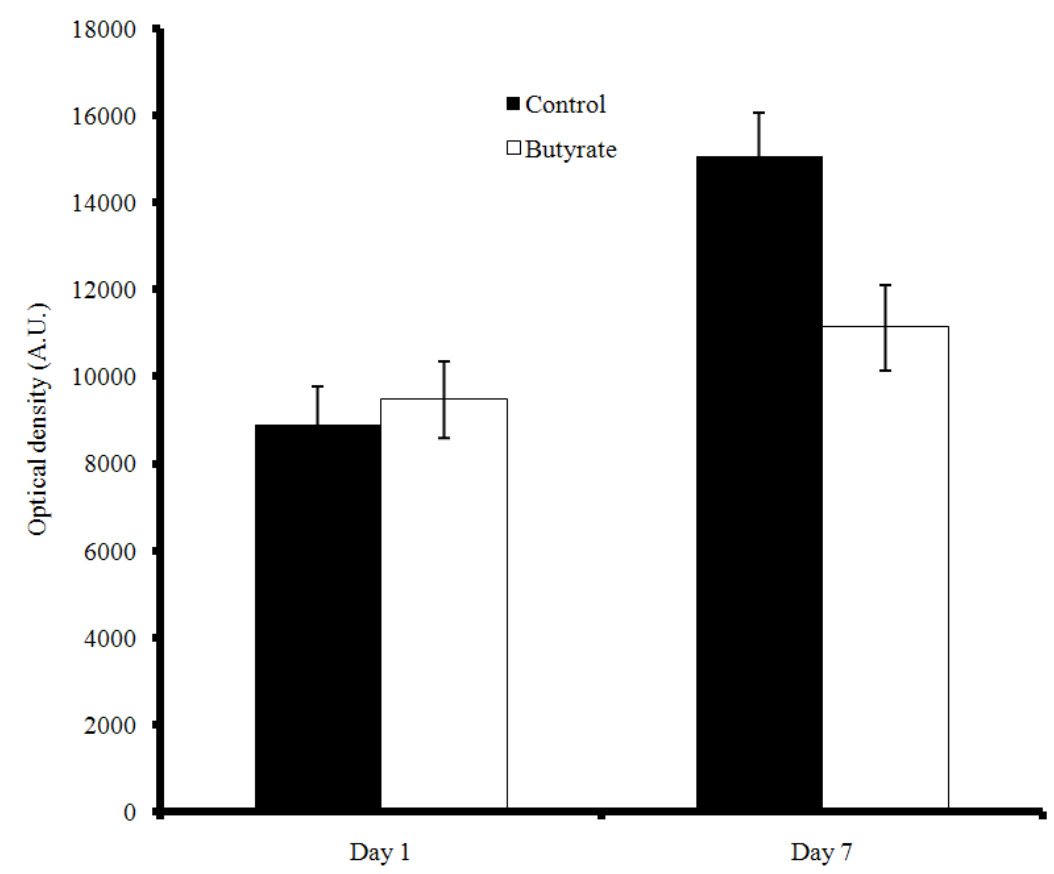

Fig. 5. NBC1 protein abundance in the rumen epithelium stratum basale of Holstein cows fed a high NFC TMR with and without exogenous butyrate dosed at $2.5 \% \mathrm{DMI}$

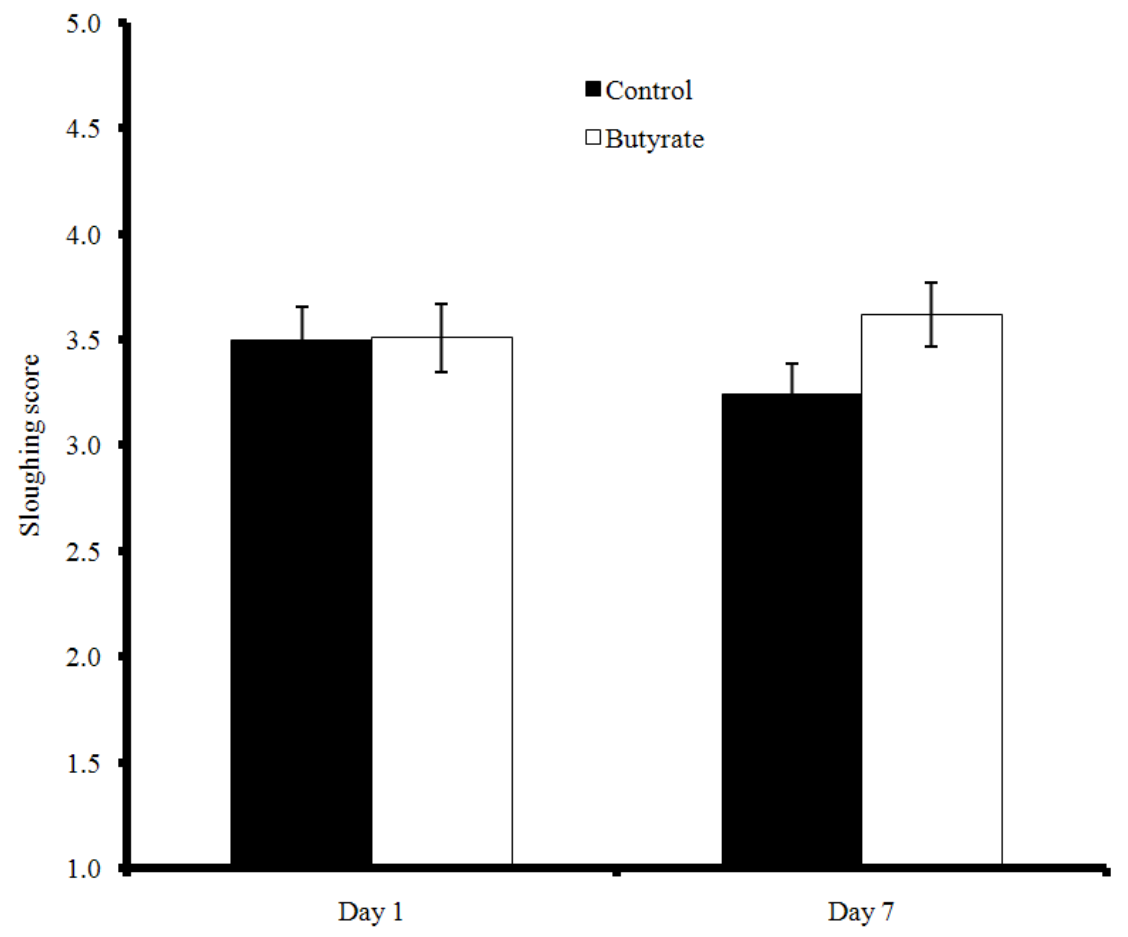

Fig. 6. Papillae sloughing score in the rumen epithelium of Holstein cows fed a high NFC TMR with and without exogenous butyrate dosed at $2.5 \% \mathrm{DMI}$ 
Anne Hermen Laarman et al. / American Journal of Animal and Veterinary Sciences 8 (4): 220-229, 2013

Table 1. Protein abundance of membrane transport proteins in stratum basale of rumen epithelium of Holstein Dairy cows dosed or not dosed with butyrate at $2.5 \%$ of DMI

\begin{tabular}{llllllll}
\hline & Day 1 & & Day 7 & & & \\
& - & & & & \\
Protein & Control & Butyrate & Control & Butyrate & Treatment & Time & Treatment*Time \\
\hline MCT1 & $11043 \pm 953$ & $8996 \pm 1018$ & $11275 \pm 953$ & $14747 \pm 953$ & 0.48 & 0.01 & 0.01 \\
NHE1 & $8286 \pm 1212$ & $9720 \pm 1243$ & $12448 \pm 2463$ & $10241 \pm 2463$ & 0.82 & 0.19 & 0.30 \\
NHE3 & $9692 \pm 1170$ & $10035 \pm 1243$ & $13329 \pm 1243$ & $13049 \pm 1243$ & 0.97 & 0.02 & 0.79 \\
NBC1 & $8897 \pm 878$ & $9458 \pm 878$ & $15065 \pm 992$ & $11122 \pm 992$ & 0.15 & $<0.01$ & 0.01 \\
\hline
\end{tabular}

\section{DISCUSSION}

The existence of MCT-1, NHE-1, NHE-3 and NBC-1 proteins in the rumen epithelium has been previously characterized (Graham and Simmons, 2005). Our aim was to quantify protein abundance and study differences in protein abundance as affected by exogenous butyrate. Previous research has shown a bioactive effect of butyrate on the mRNA expression on NHE3 (Kiela et al., 2003) and MCT-1 (Laarman et al., 2012).

The ruminal butyrate dosing reported in this study is reflected in the pronounced difference in BHBA levels detected and was not due to endogenous factors. Specifically, butyrate is taken up from the rumen and largely me-tabolized into ketone bodies and $\mathrm{CO} 2$ (Bergman, 1990). Serum BHBA concentration increased in the Butyrate treatment, suggesting an enhancement of butyrate transport across the rumen epithelium.

\subsection{Effect of Time}

Two days prior to the start of the experiment, a grain supplement was added to the TMR in stages so that by the day prior to the start of the experiment, NFC in the diet had been elevated to $44.0 \%$. Increasing the NFC of the diet increases readily-available rapidly-fermentable carbo-hydrates and can pose a considerable acidotic challenge. Indeed, both the Control and Butyrate treatments experi-enced an average of $536 \mathrm{~min} / \mathrm{d}$ and $598 \mathrm{~min} / \mathrm{d}$ of acidosis respectively, equivalent to $9-10 \mathrm{~h}$ per day. Thus, the effect of time, as measured in our experiment, is likely a physiological response to acidosis.

In other studies, higher inclusion of dietary concentrates increased MCT1 protein abundance, both when compared to an all-forage diet (Kuzinski and Rontgen, 2011) and in unrestricted access as compared to restricted access, despite similar SCFA concentrations (Koho et al., 2011). In our study, the increase in MCT1 and NHE3 on epithelial cells appears to be primarily aimed at maintain-ing intracellular $\mathrm{pH}$. Both NHE3 and MCT1 are proton exporters (Aschenbach et al., 2011), while NBC1 is a bi-carbonate importer (Connor et al.,
2010). These points suggest that the rumen epithelium is adapting to the acido-sis by increasing proton export, decreasing acidotic pres-sure and increasing bicarbonate import and thus increas-ing acid buffering capacity. Intracellular monocarboxylates present a considerable challenge for ruminal epithelial cells (Mueller et al., 2002) as they can significantly affect acid/base homeostasis in the rumen.

Decreased mucosal $\mathrm{pH}$ induces an increase in acetate uptake that is driven primarily by intracellular bicarbonate; this bicarbonate is primarily derived from exogenous sources (Aschenbach et al., 2009). In our case, the upregulation of NBC1 protein likely contributes to the $\mathrm{HCO}_{3}$-uptake capacity of the rumen epithelium. Uptake of $\mathrm{HCO}_{3}$ through $\mathrm{NBC}$ was previously shown to be, along with apical NHE activity, an important regulator of intracellular $\mathrm{pH}$ in rumen epithelial cells (Huhn et al., 2003). Combining the increased abundance of NBC1, MCT1 and NHE3 proteins, there is thus evidence that the rumen epithelium increases its capacity for intracellular $\mathrm{pH}$ regulation in response to a sustained ruminal acidotic challenge.

\subsection{Effect of Treatment}

Increased MCT1 expression not only increases monocarboxylate export, it also increases proton export from the cytosol. This proton expulsion puts an alkalotic pressure on the intracellular $\mathrm{pH}$. Intracellular SCFA are preferentially shuttled into the bloodstream by MCT1; this pro-cess is $\mathrm{HCO}_{3}$-dependent (Dengler et al., 2013). Since MCT1 activity also expels a proton from the cytosol for every monocarboxylate transported, $\mathrm{HCO}_{3}$ import via $\mathrm{NBC} 1$ may not be needed for maintenance of cellular $\mathrm{pH}$ (Aschenbach et al., 2011). Instead, basolateral MCT1 may be primarily used for SCFA export.

To increase basolateral export of SCFA, more apical SCFA import is needed to replenish the intracellular supply of SCFA. Under normal physiological conditions, low intracellular $\mathrm{pH}$ induces global histone deacetylation through the Histone Deacetylase Complex (HDAC) in order to provide an important source of acetate for 
basolateral MCT1 activity, resulting in acetate and proton export (McBrian et al., 2013). However, butyrate is an HDAC inhibitor (Davie, 2003), hence SCFAmediated MCT1 activity is likely due to exogenous butyrate.

One of the principal SCFA uptake mechanisms is apical SCFA/ $\mathrm{HCO}_{3}$ exchange. Apical $\mathrm{HCO}_{3}$ extrusion, important for SCFA uptake and most of the $\mathrm{HCO}_{3}$, is likely to come from basolateral import rather than intracellular Carbonic Anhydrase 2 (CA2) activity, given the former's much greater ability to drive acetate uptake at low ruminal $\mathrm{pH}$ (Aschenbach et al., 2009). However, since the expression of $\mathrm{NBC} 1$ was downregulated in this study, it appears that the increased NHE3 abundance may counter alkalization from apical $\mathrm{SCFA} / \mathrm{HCO}_{3}$ exchange by recycling a proton into the rumen.

NHE3 may play an important role in intracellular $\mathrm{pH}$ regulation as well, as apical exchangers have been shown to be more essential in intracellular $\mathrm{pH}$ recovery after an acidotic challenge (Sellin and De Soignie, 1998). That NHE3 was not affected by the butyrate treatment may be because of the fact that NHE3 activity and protein abundance are strongly influenced by local concentrations of SCFA and not by SCFA metabolites (Musch et al., 2001). Further, salivary sodium is also an important modulator of apical NHE activity (Sehested et al., 1996), so factors other than butyrate may have negated any effect by butyrate. Together, this suggests that the levels of exogenous butyrate used in our trial may have been insufficient to trigger an additional upregulatory response in NHE3.

\section{CONCLUSION}

This study focused on the protein abundance of membrane transport proteins involved in SCFA shuttling across the epithelial barrier as well as membrane transport proteins involved in intracellular $\mathrm{pH}$ homeostasis. Our findings indicate that a sustained acidotic challenge for a period of one week will induce changes in the protein abundance of NHE3 on the apical membrane and $\mathrm{NBC1}$ and MCT1 on the basolateral membrane. Collectively, these changes indicate that the rumen epithelium adapts to increase proton expulsion and increase bicarbonate uptake. The time*treatment interactions suggest that butyrate leads to downregulation of $\mathrm{NBC1}$ and $\mathrm{MCT} 1$, suggesting an increased capacity for transepithelial SCFA transport through MCT1. Adding exogenous butyrate to cows with SARA clearly highlights the plasticity of the membrane transport proteins in the rumen epithelium.
While this study exhibited the effects of butyrate on key membrane transport proteins, a dose response could not be elucidated because only one concentration of butyrate was used. Further, while the membrane protein abundance certainly indicated transport capacity of the rumen epithelium, it does not necessarily imply transport rates. With an abundance of literature on SCFA transport rates in the rumen epithelium, some of which is cited elsewhere in this article, future studies ought to focus on linking protein abundance to transport rates, given the importance of the latter on susceptibility to SARA. Such studies will aid in our understanding of which SCFA proteins are most important and which have the biggest effect on transport rates.

\section{ACKNOWLEDGEMENT}

We would like to thank the staff at Ponsonby Dairy Research Station for their assistance in carrying out the study. Also, funding from the Natural Science and Engineering Research Council of Canada and the Ontario Ministry of Agriculture, Food and Rural Affairs is acknowledged. We would also like to acknowledge the Ontario Ministry of Agriculture, Food and Rural Affairs' for the High Quality Personnel Graduate Scholarship to Anne Laarman. Lastly, we would like to thank Ivan Girard of Probiotech Inc., for his donation of Proformix butyrate to this study.

\section{REFERENCES}

Allen, M.S., 1997. Relationship between fermentation acid production in the rumen and the requirement for physically effective fiber. J. Dairy Sci., 80: 14471462. DOI: $10.3168 / j d s . S 0022-0302(97) 76074-0$

AlZahal, O., B. Rustomo, N. Odongo, T. Duffield and B. McBride, 2007. Technical note: A system for continuous recording of ruminal $\mathrm{pH}$ in cattle. J. Anim. Sci., 85: 213-217. DOI: 10.2527/jas.2006-095

Aschenbach, J.R., G.B. Penner, F. Stumpff and G. Gabel, 2011. Ruminant nutrition symposium: Role of fermentation acid absorption in the regulation of ruminal pH. J. Anim. Sci., 89: 1092-1097. DOI: 10.2527/jas.2010-3301

Aschenbach, J.R., S. Bilk, G. Tadesse, F. Stumpff and G. Gabel, 2009. Bicarbonate-dependent and bicarbonate-independent mechanisms contribute to nondiffusive uptake of acetate in the ruminal epithelium of sheep. Am. J. Physiol-Gastr. L., 296: G1098-G1098. DOI: 10.1152/ajpgi.90442.2008 
Bergman, E.N., 1990. Energy contributions of volatile fatty acids from the gastrointestinal tract in various species. Physiol. Rev., 70: 567-590. PMID: 2181501

Connor, E.E., R.W. Li, R.L. Baldwin and C. Li, 2010. Gene expression in the digestive tissues of ruminants and their relationships with feeding and digestive processes. Animal, 4: 993-1007. DOI: $10.1017 / \mathrm{S} 1751731109991285$

Davie, J.R., 2003. Inhibition of histone deacetylase activity by butyrate. J. Nutr., 133: 2485S-2493S. PMID: 12840228

Dengler, F., R. Rackwitz, F. Benesch, H. Pfannkuche and G. Gabel, 2013. Bicarbonate-dependent transport of acetate and butyrate across the basolateral membrane of sheep rumen epithelium. Acta Physiol (Oxf). DOI: 10.1111/apha.12155

Dionissopoulos, L., A.H. Laarman, O. AlZahal, S.L. Greenwood and M.A. Steele et al., 2013. Butyratemediated genomic changes involved in non-specific host defenses, matrix remodeling and the immune response in the rumen epi-thelium of cows afflicted with subacute ruminal acido-sis. Am. J. Anim. Vet. Sci., 8: 8-27. DOI: 10.3844/ajavssp.2013.8.27

Gabel, G., J.R. Aschenbach and F. Muller, 2002. Transfer of energy substrates across the ruminal epithelium: Im-plications and limitations. Anim. Health. Res. Rev., 3: 15-30. PMID: 12400867

Gavet, O. and J. Pines, 2010. Progressive activation of CyclinB1-Cdk1 coordinates entry to mitosis. Dev. Cell, 18: 533-543. DOI: 10.1016/j.devcel.2010.02.013

Graham, C. and N.L. Simmons, 2005. Functional organization of the bovine rumen epithelium. Am. J. Phys. Regulatory, Integr. Comparative Physiol., 288: R173-R181. DOI: 10.1152/ajpregu.00425.2004

Huhn, K., F. Muller, K.U. Honscha, H. Pfannkuche and G. Gabel, 2003. Molecular and functional evidence for a $\mathrm{Na}^{+} / \mathrm{HCO}_{3}{ }^{-}$-cotransporter in sheep ruminal epithelium. J. Comp. Physiol. B., 173: 277-284. DOI: $10.1007 / \mathrm{s} 00360-003-0333-0$

Kiela, P.R., J. LeSueur, J.F. Collins and F.K. Ghishan, 2003. Transcriptional regulation of the rat NHE3 gene Functional interactions between GATA-5 and Sp fami-ly transcription factors. J. Biol. Chem., 278: 5659-5668. DOI: 10.1074/jbc.M209473200

Kiela, P.R., N. Kuscuoglu, A.J. Midura, M.T. MiduraKiela and C.B. Larmonier et al., 2007. Molecular mechanism of rat NHE3 gene promoter regulation by sodium butyrate. Am. J. Physiol. Cell Physiol., 293: C64-C74. DOI: 10.1152/ajpcell.00277.2006
Koho, N.M., J. Taponen, H. Tiihonen, M. Manninen and A.R. Poso, 2011. Effects of age and concentrate feeding on the expression of MCT 1 and CD147 in the gastrointestinal tract of goats and Hereford finishing beef bulls. Res. Vet. Sci., 90: 301-305. DOI: $10.1016 /$ j.rvsc. 2010.06 .002

Krause, K.M. and G.R. Oetzel, 2006. Understanding and preventing subacute ruminal acidosis in dairy herds: A review. Anim. Feed Sci. Technol., 126: 215-236. DOI: $10.1016 /$ j.anifeedsci.2005.08.004

Kuzinski, J. and M. Rontgen, 2011. The mRNA and protein expression of ruminal MCT1 is increased by feed-ing a mixed hay/concentrate diet compared with hay ad libitum diet. Arch. Tierzucht., 54: 280286. DOI: 10.1152/ajpregu.00597.2011

Laarman, A.H., 2011. Ruminal acidosis in dairy calves during the weaning transition. MSc Thesis, University of Alberta.

Laarman, A.H., A.L. Ruiz-Sanchez, T. Sugino, L.L. Guan and M. Oba, 2012. Effects of feeding a calf starter on molecular adaptations in the ruminal epithelium and liver of Holstein dairy calves. J. Dairy Sci., 95: 25852594. DOI: $10.3168 /$ jds.2011-4788

Lecona, E., N. Olmo, J. Turnay, A. Santiago-Gomez and I. Lopez de Silanes et al., 2008. Kinetic analysis of butyrate transport in human colon adenocarcinoma cells reveals two different carrier-mediated mechanisms. Biochem. J., 409: 311-320. DOI: 10.1042/BJ20070374

Mathew, O.P., K. Ranganna and F.M. Yatsu, 2010. Butyrate, an HDAC inhibitor, stimulates interplay between different posttranslational modifications of histone $\mathrm{H} 3$ and differently alters $\mathrm{G} 1$-specific cell cycle proteins in vascular smooth muscle cells. Biomed. Pharmacotherapy, 64: 733-740. DOI: 10.1016/j.biopha.2010.09.017

McBrian, M.A., I.S. Behbahan, R. Ferrari, T. Su and T.W. Huang et al., 2013. Histone acetylation regulates intracellular pH. Mol. Cell, 49: 310-321. DOI: 10.1016/j.molcel.2012.10.025

Mueller, F., K. Huber, H. Pfannkuche, J.R. Aschenbach and G. Breves et al., 2002. Transport of ketone bodies and lactate in the sheep ruminal epithelium by mono-carboxylate transporter 1. Am. J. Physiol Gastrointest Liver Physiol., 283: G1139-G1146. DOI: 10.1152/ajpgi.00268.2001

Musch, M.W., C. Bookstein, Y. Xie, J.H. Sellin and E.B. Chang, 2001. SCFA increase intestinal $\mathrm{Na}$ absorption by induction of NHE3 in rat colon and human intestinal C2/bbe cells. Am. J. Physiol-Gastr. L., 280: G687-G693. PMID: 11254495 
Penner, G.B., J.R. Aschenbach, G. Gabel, R. Rackwitz and M. Oba, 2009. Epithelial capacity for apical uptake of short chain fatty acids is a key determinant for intraruminal $\mathrm{pH}$ and the susceptibility to subacute ru-minal acidosis in sheep. J. Nutr., 139: 1714-1720. DOI: 10.3945/jn.109.108506

Sehested, J., L. Diernaes, P.D. Moller and E. Skadhauge, 1996. Transport of sodium across the isolated bovine rumen epithelium: Interaction with shortchain fatty acids, chloride and bicarbonate. Exp. Physiol., 81: 79-94. PMID: 8869141

Sellin, J.H. and R. De Soignie, 1998. Short-chain fatty acids have polarized effects on sodium transport and in-tracellular $\mathrm{pH}$ in rabbit proximal colon. Gastroenterology, 114: 737-747. DOI: 10.1016/S0016-5085(98)70587-6
Steele, M.A., G. Vandervoort, O. AlZahal, S.E. Hook and J.C. Matthews et al., 2011. Rumen epithelial adaptation to high-grain diets involves the coordinated regulation of genes involved in cholesterol homeostasis. Physiol. Genom., 43: 30816. DOI: 10.1152 physiolgenomics.00117.2010

Steele, M.A., O. AlZahal, C. Zettler, J.C. Matthews and B.W. McBride, 2013. Rumen epithelial adaptation dur-ing the transition period is associated with structural changes and transcriptomic signatures. Proceedings of the ADSA-ASAS Joint Annual Meeting, Jul. 8-12.

Williamson, D.H., J. Mellanby and H.A. Krebs, 1962. Enzymic determination of D(-)-beta-hydroxybutyric acid and acetoacetic acid in blood. Biochem. J., 82: 90-90. PMID: 14007241 